\title{
Classroom Instructions Observed from the Perspectives of Current Reform in Science Education: Comparisons between Korean and U.S. Classrooms
}

\author{
Todd Campbell \\ Utah State University, Utah, USA \\ Phil Seok Oh and Myeong-Kyeong Shin \\ Gyeongin National University of Education, Gyeonggi, REPUBLIC OF KOREA \\ Danhui Zhang \\ Beijing Normal University, Beijing, CHINA
}

This research investigated the similarities and differences between Korean and U.S. 9-12 ${ }^{\text {th }}$ grade science classrooms. The Reformed Teaching Observation Protocol was used to observe sixty-six classrooms (26 Korean and 40 U.S.) to examine the extent to which principles of constructivism framing both Korean and U.S. standards documents were observed. Through quantitative methods the findings revealed generally more similarities than differences when comparing Korean and U.S. classrooms. This was evidenced by the lack of overall significant differences in how the classrooms were rated, as well as the lack of overall significant differences in each subscale of reformed teaching measured by the RTOP (Lesson Design, Content \& Process, \& Classroom Culture). But, Student and Teacher Relations, one of the two subscales of Classroom Culture in the RTOP was found to be different with U.S. teachers rated significantly higher than the Korean teachers. Our findings have led us to conclude that there is still significant room for improvement in both Korea and the U.S. in aligning student experiences in science classrooms with those visions outlined by reform efforts framed by principles of constructivism.

Keywords: Abstraction, Conceptual Development, Conceptual Change

\section{INTRODUCTION}

[T] he taken-for-granted familiar educational practices, beliefs and attitudes in one country can be exposed, made 'strange' and questioned when researchers from two

Correspondence to: Todd Campbell, Assistant Professor of Science Education, School of Teacher Education and Leadership, Utah State University 2805 Old Main Hill, Logan, UT, USA E-mail: todd.campbell@usu.edu countries collaborate on research involving teaching and learning in two countries. (Aldridge \& Fraser, 2000, p. 102)

Much research is available demonstrating that Asian students (i.e. Chinese, Japanese, and Korean) outperform American students in science (Zhou \& Peverly, 2004; Zhou, Peverly, Boehm, \& Chongde, 2000). Additionally, there are many suggested reasons for why these achievement gaps are consistently found, including curriculum policy (Suter, 2000), linkages between formal and informal learning, and local 


\section{State of the literature}

- It is well-documented that Asian students (i.e. Chinese, Japanese, and Korean) outperform American students in science.

- There are many suggested reasons for why Asian and American students' science achievement gaps are consistently found, including curriculum policy, linkages between formal and informal learning, and local variations within the U.S. when compared to most Asian Countries.

- There exist relatively few studies of the differences in classroom features of Korean and U.S. classrooms when considering current reform derived from research in teaching and learning framed by constructivism.

- Leading national science education reform documents in both Korean and the U.S. acknowledge the importance of classroom instruction as a change agent and highlight instructional strategies as central determinants of reform.

\section{Contribution of this paper to the literature}

- There existed a greater variability in factors influencing classroom environments when comparing Korean and U.S. Classrooms providing opportunity for deepened insight that may not have emerged as these countries were studied in isolation.

- The findings illuminate the resilience of traditional instructional strategies across international boundaries even when a confluence of geographic, social and cultural influences is present.

- The findings suggest that reformed teaching practices are unlikely to be strong enough to be a deciding factor in explaining the outperformance of Asian students in science.

variations within the U.S. when compared to most Asian Countries (Lee, 1998). While there may be many comparisons made considering student achievement in science between Asian and American students and suggested explanations for these differences, there exist relatively few studies of the differences in classroom features when considering current reform derived from research in teaching and learning framed by constructivism. Fraser (1996) articulated the following two reasons supportive of educational research across national boundaries: 1) there exists a greater variability in factors influencing classroom environments and 2) insight is provided about other countries, while insight into the classroom environment of the researchers' own country is sharpened. The National Science Education
Standards (NSES) (National Research Council [NRC], 1996) is a leading reform document in the United States, while in Korea it is the Science Curriculum officially announced by the Ministry of Education (Ministry of Education [MOE], 1997; Ministry of Education and Human Resources Development [MOE HRD], 2007) that envisions a reformed science education in schools. Both documents acknowledge the importance of classroom instruction as a change agent and highlight instructional strategies as central determinants of reform. As an example of the importance of instructional strategies, in the U.S. standards document (NRC, 1996) inquiry is included both as a content standard alongside other more traditional content standards (i.e. Life Sciences, Physical Sciences, \& Earth and Space Science) and is framed as the central instructional strategy for teaching science. Similarly, in the Korean standards document inquiry is also highlighted as an important instructional strategy (MOE, 2007).

Because of the common instructional reform pursuits of Korean and U.S. standards documents and the recognized difference in student achievement when comparing Asian and American students, this particular study is focused on identifying the similarities and differences found when comparing classroom teaching and learning between one Asian country (South Korea) and the U.S. with respect to reformed teaching. Given this aim, the following more formally articulated research question guided this study:

What similarities and differences can be discovered in the classroom instruction when comparing Korean and U.S. 9-12th grade science classrooms using a reform-oriented observational instrument?

It is expected that the findings emerging from this study can offer some insight into the possible role instructional practices play in influencing the achievement gaps when comparing Asian and American students in science. At the same time this study can provide useful information for professional developers in science education considering how to best help teachers recognize the reform visions of each countries standards document. Thus, the primary goal of this research is to elucidate those instructional qualities that may be masked by what Fairclough (1995) described as the naturalization or opacity of an established ideology when considered in an isolated context.

\section{Theoretical Background}

\section{Science Education Reform and Constructivism}

One of the main driving forces of current reform in science education is constructivism. In a broad sense, constructivism is a theory focused on the nature of learning whereby "knowledge forms are said to be 
fashioned or constructed by learners" (Hruby, 2002, p. 585). Different theorists influential in the development of constructivism offer distinctive hues of this theory. Piaget's work centered upon the individual's construction of knowledge as the learner makes sense of the world by assimilating or accommodating new experiences with previously developed schema (Oxford, 1997). Put more succinctly, "Piaget believed that human beings possess mental structures that assimilate external events, and convert them to fit their mental structures. Moreover, mental structures accommodate themselves to new, unusual, and constantly changing aspects of the external environment" (Bhattacharya \& Han, 2001). Palmer (2005) described this as the "cognitive constructivist" (p. 1854) viewpoint because of the emphasis on individuals.

Lev Vygotsky's views of learning were more concerned with the role of society, culture, and language in knowledge construction (Vygotsky, 1978). Hruby (2002) described this in terms of social constructivism by explaining that "human beings are inherently social and that therefore learning is a social process of developing understanding such that they reflect the knowledge and forms of knowing that are held privileged within one's community" (p. 585). In the social constructivist frame, learning is mediated through social exchange; with much learning occurring as learners interact with more competent adults. During the social interaction, students participate in the process of developing knowledge and appropriate the newly developed knowledge into their own minds.

While these two forms of constructivism are quite different in many ways and by no means exhaustive, there are commonalities that exist between these two and the others. Constructivism, generally speaking, leads to educative approaches "in which learners actively create, interpret, and reorganize knowledge" (Gordan, 2008 , p. 324). Windschitl (1999) describes this characteristic as follows:

[T]hese fluid intellectual transformations occur when students reconcile formal instructional experiences with their existing knowledge, with the cultural and social contexts in which ideas occur, and with a host of other influences that serve to mediate understanding ( $p .2)$.

Thus, constructivism posits that student learning occurs actively as students are given time, space, and support to cultivate meanings of their experiences in the context of their current understandings and environments.

When student learning framed by constructivism is considered in the context of what characterizes science instruction, Piaget and Dewey as well as many others are credited with shifting the focus of learning "to involve students in doing rather than being told or only reading about science ... [where] teaching models were based on theories of learning that emphasized the central role of students' own ideas and concrete experiences in creating new and deepened understandings of scientific concepts" (NRC, 2000, p. 16-17). Scientific inquiry is one instructional approach put forth in this vein in science education. In the U.S., the NSES (NRC, 1996) as well as other standards documents (American Association for the Advancement of Science [AAAS], 1990, 1993) and leading science teaching organizations (National Science Teachers Association [NSTA], 2007) all consider student inquiry as a central strategy for instruction in the science classroom at all grade levels. Likewise in Korea, the Science Curriculum (MOE HRD, 2007) promotes scientific inquiry, stating " $t$ the core concepts of science are taught with a close relationship to learners' experience and students are provided with the opportunity to apply science related knowledge and inquiry skills for problem solving in society and daily life" (p. 2).

By examining the following five principles of engaging students in scientific inquiry outlined in the NRC (2005), we can quickly see how engaging students in doing science aligns with constructivism: 1) Framing research questions, 2) Designing investigations, 3) Conducting investigations, 4) Collecting data, and 5) Drawing conclusions. As students are engaged in the principles of scientific inquiry, they can be found relying on their prior knowledge base to frame research questions, designing investigations in ways aligned with what they have seen in other examples but have perhaps modified to meet the immediate needs of a particular inquiry, conducting investigations, and collecting data where they gain firsthand experiences to draw on in creating new understandings. Finally, students are asked to draw conclusions by reconciling what they learned from their investigations with what they knew previously.

In addition to engaging students in scientific inquiry as an instructional approach, other changes in teaching emphases that are aligned with constructivism are outlined. In the U.S., the NSES describe teaching consistent with the constructivism that

- Focus and support inquiries while interacting with students.

- Orchestrate discourse among students about scientific ideas.

- Challenge students to accept and share responsibility for their own learning.

- Recognize and respond to student diversity and encourage all students to participate fully in science learning.

- Encourage and model the skills of scientific inquiry as well as the curiosity, openness to new ideas and data, and skepticism that characterize science (NRC, 1996, p. 32).

In both Korea and the U.S., instructional approaches like these are promoted so that they allow students to 
develop understanding from their own inquiry experiences and connect them to scientific concepts and ideas (AAAS, 1990; MOE, 1997; MOE HRD, 2007; NRC, 1996).

\section{The impact of constructivism and reform efforts in Korea and the U.S.}

Ascertaining the extent to which reform efforts framed by constructivism and promoted in standards documents have taken hold has been a topic of discussion in both countries. In Korea, Lee and Fraser (2000) argued, "while constructivist principles have been consistently emphasized in the science curriculum since 1982, actual practices in the classrooms in Korea have been dominated by teacher-centered, lecture-type instruction" (p. 1). As evidence for this claim, in the study completed by Kim, Fisher, and Fraser (2000) investigating students' perceptions of their learning environment and teacher interpersonal behaviors in Korean science classrooms, 543 grade eight students rated the level of support they received from their teachers as relatively low. In addition, these same students reported a minimal amount of involvement in their class, as well as a limited amount of cooperation with other students. In another study of Korean science classrooms, Lee, Fraser, and Fisher (2003) surveyed 439 high school students and found that "teacher-student interactions in Korean senior high school science classrooms reflect the general image of the youth-elder relationship in society of 'directing teachers and obeying students"' (p. 83). Each of these studies along with Lee and Fraser's (2000) proclamation suggests that teaching and learning framed by constructivism may be inhibited in 'teacher-dominated' classrooms in Korea. When examining the current science textbooks for elementary and middle schools, however, it is found that more student-centered inquiry activities are included than before. But, more recent research investigating barriers to Korean teachers' enactment of reformed instructional practices, including inquiry instructional strategies, found teachers' concerns that including dealing with 'right answers' in these contexts, teaching correct concepts, fear of losing face if something goes wrong, and fears of dealing with the messiness of learning in an inquiry environment (Kim \& Tan, 2010). Therefore, it can be said that studentcentered approaches in science teaching are accepted at the level of textbook developers and science educators, while teaching practices found in classrooms lag behind.

Similar to the experiences that have been documented for Korean students in science, U.S. science classrooms are also found dominated by teacher-centered instructional practices (NRC, 2005; O'Sullivan \& Weiss, 1999; Windschitl, 2003). Windschitl (2003) stated:
For a science student, developing one's own question and the means to resolve the question suggests an inquiry experience that is profoundly different from the far more common tasks of science schooling which consist of answering questions prescribed in the curriculum using methods also preordained in the curriculum or by the classroom teacher (p. 114 ).

Additional insights about U.S. classrooms are revealed in the findings of the 2000 National Survey of Science and Mathematics Education. This was a study that surveyed 5,765 science and mathematics teachers in schools across the United States. The findings from this study indicated that 1) students in 9-12 science classrooms predominantly experience lecture as an instructional strategy and 2) the majority of instruction encountered was not aligned with standards-based teaching practices (Banilower, 2002; Smith, 2002; Weiss, 2002; Wood, 2002).

In addition to these findings about U.S. classrooms which reflect the extent to which students are or are not able to engage in learning characterized by constructivism, America's Lab Report: Investigations in High School Science (NRC, 2005) reported that "few current laboratory experiences incorporate ongoing reflection and discussion between and among the teacher and the students, although there is evidence that such reflection and discussions are essential to help students make meaning out of their laboratory activities" (p. 133-134). Each of these studies suggests teacher-dominated approaches also influence U.S. classrooms as they do Korean classrooms.

\section{A framework for investigating science classroom instruction}

When considering mechanism appropriate for investigating science classroom instruction, several studies have recently been completed in the U.S. with the framework adopted in this current study. The Reformed Teaching Observation Protocol (RTOP) is a tool that was created in the U.S. "as an observational instrument designed to measure 'reformed teaching"'(Piburn et al., 2000). The instrument was developed as aligned with the principles of constructivism which framed the U.S. standards documents (AAAS, 1990; National Council of Teachers of Mathematics [NCTM], 2000; NRC, 1996) as well as the Korean national science curriculum (MOE, 1997; MOE HRD, 2007). The RTOP consists of 25 items divided into three subsets: Lesson Design and Implementation, Content, and Classroom Culture. Content and Classroom Culture are each divided into two smaller groups. Content is divided into Propositional Knowledge and Procedural Knowledge, while Classroom Culture is divided into Communicative Interactions and Student/Teacher Relationships. The 
Design and Implementation subset was designed to capture the "model for reformed teaching. It describes a lesson that begins with recognition of students' prior knowledge and preconceptions, that attempts to engage students as members of a learning community, that values a variety of solutions to problems, and that often takes its direction from ideas generated by students (Piburn et al. , 2000, p. 8)". The Content subset was designed to "assessed the quality of the content of the lesson, and . . . the process of inquiry" (Piburn et al. , 2000 , p. 8). Finally, the Classroom Culture subset, was directed at "the climate of the classroom" (Piburn et al., 2000 , p. 9). The RTOP items are rated by trained classroom observers on a scale of $0-4$, with 0 signifying the item never occurred and 4 signifying the item is very descriptive of the classroom observed. Additional information about the theoretical constructs guiding the design of the instrument, along with reliability and validity information and results of an exploratory factor analysis of the RTOP can be found in Piburn et al. (2000).

In addition to the RTOP being aligned with principles of constructivism framing standards documents in both Korean and the U.S. and the established validity and reliability of the observation instrument, it has also proven useful in recent studies investigating reformed teaching. As an example, Sawada, et al. (2002) found correlation coefficients ranging from 0.88 to 0.97 between RTOP scores for classrooms observed and mean normalized gain scores for students in those classrooms. Adamson et al. (2003) used the RTOP to investigate the extent to which undergraduate biology pre-service students who were taught in ways aligned with reformed teaching subsequently taught in a similar manner. They found that the preservice biology teachers who did take undergraduate coursework aligned with reformed teaching were subsequently observed teaching similarly while their students achieved significantly higher with respect to scientific reasoning, nature of science, and biological concepts. Collectively, because the RTOP is aligned with principles of constructivism, it has established validity and reliability, and has proven useful for measuring reformed teaching in other recent studies, it was selected as the framework to guide the data collection and lens for understanding classroom instruction adopted for this current research.

\section{METHODS}

\section{Context}

Data for this study came from sixty-six 9-12th grade science classrooms (26 Korean and 40 U.S.). The Korean data was obtained from videotapes submitted by 26 Korean science teachers prior to their attending a professional development workshop from 2000 to 2004. One class period was observed for each participant in the Korean sample. The data for the U.S. teachers was collected through a stratified random sampling of the school districts in Utah (district size, socioeconomic status of students served by districts, and district student diversity served as the stratifying agents). One class period of instruction was also observed for each of the 40 U.S. participants during the years 2006 and 2007. No videotapes were collected in the U.S., instead classroom observations were completed in person by a group of three U.S. researchers. Before visiting the 40 U.S. classrooms, the U.S. researchers participated in a oneday training session with a competent trainer/researcher experienced in using the instrument. The three project team members established inter-rater reliability with the RTOP through trial ratings of videocassettes from classrooms instructed by teachers not participating in the project. Inter-rater reliability was established at two stages during the U.S. classroom observation period, once before beginning classroom observations and again two and one half months into the five-month classroom observation window. At each stage inter-rater reliability was determined to be at or greater than .80 . The data sampling is classified as a convenience sample because it was taken from the regions where Korean and U.S. researchers were based. Additionally, this data was seen as informative, because in both countries, it was collected prior to any educational intervention or professional development. It was seen as a sample that could provide an accurate vision of the typical instruction found in science classrooms in both countries. In summary, data from these two countries, more specifically, were selected because of 1) the similarities between national reform documents, 2) the capacity of this sample to inform discussion about the influence of classroom instruction with regards to the outperformance of Asian students in comparison to U.S. students, and 3) access to convenience samples in two countries where these findings can inform future national reform efforts in these two countries and the subsequent research of the authors of this specific research.

Prior to the start of this research one of the three U.S. researchers collaborated with the Korean researchers to lead the completion of online RTOP training. Through this process, the three project team members (one U.S. researcher and 2 Korean researchers) established inter-rater reliability at or greater than .88 among themselves and with an expert rater through trial ratings of online videos available at the training site. Given the establishment of greater than .80 rater agreement (McDavid \& Hawthorn, 2005) amongst the U.S. researcher and the two Korean researchers alongside the previously established agreement between the three U.S. researchers, the 
Table 1. Disciplines Taught by Korean and U.S. Participants

\begin{tabular}{|c|c|c|c|}
\hline & & Korean & U.S. \\
\hline & Earth Science & 22 & 3 \\
\hline Science & Biology & 0 & 20 \\
\hline Discipline/Subject & Chemistry & 2 & 12 \\
\hline Observed & Physics & 2 & 4 \\
\hline & Geology & 0 & 1 \\
\hline
\end{tabular}

Table 2. RTOP Descriptive statistics for Korean and U.S. Classrooms

\begin{tabular}{lccc}
\hline & Korean (n=26) M SD & U.S. (n=40) M SD & Max. Score Possible \\
\hline RTOP Total Score & $46.50(15.65)$ & $53.46(17.21)$ & 100 \\
Lesson Design & $8.58(3.77)$ & $8.53(3.92)$ & 20 \\
Propositional & $13.27(3.08)$ & $14.1(3.51)$ & 20 \\
Procedural & $6.69(3.64)$ & $8.45(4.12)$ & 20 \\
Communicative & $8.35(3.63)$ & $9.85(3.68)$ & 20 \\
S/T Relations & $9.62(3.89)$ & $12.55(4.62)$ & 20 \\
\hline
\end{tabular}

Table 3. Independent T-tests for RTOP and subscale comparisons of Korean and U.S. classrooms.

\begin{tabular}{lcccc}
\hline & & & & Effect size \\
& Korean Mean (SD) & U.S. Mean (SD) & t-tests & Cohen's d \\
\hline Total RTOP Scores & $46.50(15.65)$ & $53.46(17.21)$ & $t(64)=-1.672, p=.099$ & 0.42 \\
Lesson Design & $8.58(3.77)$ & $8.53(3.92)$ & $t(64)=.053, p=.958$ & 0.01 \\
Propositional & $13.27(3.08)$ & $14.1(3.51)$ & $t(64)=-.985, p=.328$ & 0.25 \\
Procedural & $6.69(3.64)$ & $8.45(4.12)$ & $t(64)=-1.798, p=.077$ & 0.45 \\
Communicative & $8.35(3.63)$ & $9.85(3.68)$ & $t(64)=-1.631, p=.108$ & 0.41 \\
S/T Relations & $9.62(3.89)$ & $12.55(4.62)$ & $t(64)=-2.679, p=.009$ & 0.69 \\
\hline
\end{tabular}

Note: Effect size Cohen's d: $>0.8$, large; $>0.5$ medium; $<0.3$ very small

Korean researchers completed all ratings of the Korean classroom videotapes, while the U.S. researchers completed all ratings of the U.S. classrooms.

Demographic information for both groups of participants studied is revealed in Table 1 . The number of teachers sampled, number of teachers observed in each discipline, as well as the years sampled were all different to some degree and recognized as potential limitations to this study.

\section{Data Analysis}

The following two data sources were used for this research: 1) Korean videotapes and 2) face-to-face U.S. classroom observations. Each of these was rated with the RTOP. Descriptive statistics were determined for the Korean and U.S. classrooms before independent Ttests were conducted to compare Korean and U.S. Teachers on total RTOP score and the five subscale scores. Finally, independent t-tests were used to compare the Korean and U.S. scores for each of the 25 items of the RTOP. All statistical analyses were conducted using the Statistical Package for Social Science (SPSS) version 16 for Windows (SPSS, 2007).

\section{RESULTS AND DISCUSSION}

\section{RTOP Subcategory}

Descriptive statistics revealed similarities between the Korean and U.S. 9-12th grade science teaching. The results are summarized in Table 2.

The total scores on the RTOP indicate that there is still significant room for improvement in science education of both Korea and U.S.. Maclsaac and Falconer (2002) described classrooms with total RTOP scores ranging from 46-55 as "partial high school reform (some group work; most discourse still with teacher)" (p. 482).

In addition to the overall ratings, there is a possible score of 20 points on each subscale. Through looking at the totals for each of the subscales, additional instructional qualities emerge about where possible improvements are most needed in each country. Within the Korean classrooms, rated mean scores ranged from highest at 13.27 for the Propositional subscale to lowest at 6.69 for the Procedural subscale. Because the subscale means, except for the Propositional subscale, were rated below 10 points or less than half of what was possible, these subscales are seen as areas for continued focus and improvement in Korean classrooms. 
Table 4. Items that indicate significantly different findings between Korea and U.S.

\begin{tabular}{|c|c|c|c|c|c|}
\hline & Korean Mean (SD) & U.S. Mean (SD) & $\mathrm{t}$ test & $\mathrm{p}$ & $\begin{array}{l}\text { Effect size } \\
\text { Cohen's d }\end{array}$ \\
\hline \multirow[b]{2}{*}{ Item 1} & $1.92(.935)$ & $2.68(.997)$ & -3.067 & $=0.003$ & 1.74 \\
\hline & \multicolumn{5}{|c|}{$\begin{array}{l}\text { The instructional strategies and activities respected students' prior knowledge and the } \\
\text { preconceptions inherent therein. }\end{array}$} \\
\hline \multirow{3}{*}{ Item6 } & $3.00(.748)$ & $3.62(.774)$ & -3.247 & $=0.002$ & 3.74 \\
\hline & \multicolumn{5}{|c|}{ The lesson involved fundamental concepts of the subject. } \\
\hline & $1.15(.834)$ & $1.68(1.163)$ & -2.117 & $=0.038$ & 0.51 \\
\hline Item13 & \multicolumn{5}{|c|}{$\begin{array}{l}\text { Students were actively engaged in thought-provoking activity that often involved the critical } \\
\text { assessment of procedures. }\end{array}$} \\
\hline \multirow{3}{*}{ Item14 } & $1.31(.884)$ & $2.07(1.163)$ & -2.865 & $=0.006$ & 0.88 \\
\hline & \multicolumn{5}{|c|}{ Students were reflective about their learning. } \\
\hline & $1.88(.909)$ & $2.53(1.240)$ & -2.417 & $=0.019$ & 1.19 \\
\hline Item 18 & \multicolumn{5}{|c|}{$\begin{array}{l}\text { There was a high proportion of student talk and a significant amount of it occurred between and } \\
\text { among students. }\end{array}$} \\
\hline \multirow{2}{*}{ Item 20} & $1.85(.967)$ & $2.97(1.050)$ & -4.401 & $<.000$ & 1.90 \\
\hline & \multicolumn{5}{|c|}{ There was a climate of respect for what others had to say. } \\
\hline \multirow{2}{*}{ Item21 } & $2.27(.874)$ & $2.90(1.215)$ & -2.449 & $=0.017$ & 1.59 \\
\hline & \multicolumn{5}{|c|}{ Active participation of students was encouraged and valued. } \\
\hline \multirow{2}{*}{ Item 23} & $2.00(.980)$ & $3.30(.883)$ & -5.597 & $<.000$ & 2.59 \\
\hline & \multicolumn{5}{|c|}{ In general the teacher was patient with students. } \\
\hline \multirow{2}{*}{ Item 25} & $1.54(.811)$ & $2.28(1.154)$ & -3.042 & $=0.006$ & 1.13 \\
\hline & \multicolumn{5}{|c|}{ The metaphor "teacher as listener" was very characteristic of this classroom. } \\
\hline
\end{tabular}

Notes: Subcategories are separated with shading in the table.

In the U.S. classrooms, rated mean scores for each of the subscales ranged from highest at 14.1 for the Propositional subscale to lowest at 8.45 for the Procedural subscale. In the U.S. sample, the means for the Lesson Design, Procedural, and Communicative subscales were rated below 10 points, signaling that these are seen as areas for more reform in U.S. classrooms.

Independent T-tests were conducted to compare Korean and U.S. teachers on total RTOP score and five RTOP subscale scores. As can be seen in Table 3, no statistically significant differences were found when comparing the overall RTOP scores. Additionally, no significant differences were found when comparing the subscales of the RTOP for Korea and U.S., except when considering the Student/Teacher Relations subscale $(\mathrm{t}(64)=-2.679, \mathrm{p}=.009)$ with a medium effect size (Cohen's $\mathrm{d}=0.69)$.

\section{RTOP Items}

Finally, independent sample t-tests comparing the Korean and U.S. scores for each of the 25 items of the RTOP indicated that 9 items out of 25 differed significantly from each other. The significantly different items are found in Table 4.

While there is only one subscale, Student/Teacher Relations, that is found to be significantly different at the subcategory level, analysis of individual items may provide insight into noteworthy differences within each subscale.

\section{Lesson Design}

The Lesson Design subscale of the RTOP was designed to assess "the model for reformed teaching. It describes a lesson that begins with recognition of students' prior knowledge and preconceptions, that attempts to engage students as members of a learning community, that values a variety of solutions to problems, and that often takes its direction from ideas generated by students" (Piburn et al. , 2000, p. 8). For both the Korean and U.S. classrooms, this scale was rated among the lowest (3rd lowest for Korean and 2nd lowest for U.S.). No statistical differences were documented when comparing Korean and U.S. classrooms on the subscale level, but statistical differences were found when individual item comparisons were completed. RTOP item 1, The instructional strategies and activities respected students' prior knowledge and the preconceptions inherent therein, was one of these items. This item "suggests an attitude of curiosity on the teacher's part, an active solicitation of student ideas, and an understanding that much of what a student brings to the . . . classroom is strongly shaped and conditioned by their everyday experiences" (Pilburn et al., 2000, p. 34). As can be seen in table 4, the U.S. teachers were rated significantly higher on this item, compared with the Korean teachers 
$(\mathrm{t}=-3.067, \mathrm{p}=0.001)$. Based on the effect size (Cohen's $\mathrm{d}=1.74$ ), we can conclude that the difference was large.

\section{Propositional and Procedural}

Because both these subscales are part of the content category of indicators in the RTOP, they are discussed here together. The Propositional subscale identifies the quality of the scientific knowledge emphasized, and the Procedural subscale reveals the quality of the process of scientific inquiry experienced by students. Although there were no statistical differences found on the subscale level when comparing Korean and U.S. classrooms for both of these subscales, the analysis of individual items within the Propositional and Procedural subscales did reveal statistically significant differences. In the Propositional subscale, item 4, The lesson involved fundamental concepts of the subject, was found to be different, with U.S. teachers rated significantly higher on this item compared with the Korean teachers $(\mathrm{t}=-3.247, \mathrm{p}=0.002)$ with a large effect size (Cohen's $d=3.74)$. Because there was no statistically significant difference across the entire Propositional subscale and because the subscale score for Korean teachers is relatively high, however, the finding from this one item is hardly believed to suggest that U.S. teachers were generally found more focused on fundamental concepts of the subjects observed (e.g. Biology, Earth Science, etc.) in comparison to the Korean teachers.

In the Procedural subscale, item 13, Students were actively engaged in thought-provoking activity that often involved the critical assessment of procedures, along with item 14, Students were reflective about their learning, were found significantly different. It should first be noted that ratings for neither country were particularly high (Table 4), but when comparing the teachers from both countries on Item 13 and 14, the U.S. teachers were rated significantly higher with respect to both of these items.

\section{Communicative and Student/Teacher Relations}

Because both the Communicative and Student/Teacher Relations subscales of the RTOP assess the classroom culture, they are discussed here in the same way that the previous two subscales were discussed. The Communicative subscale focuses on the extent to which students are involved in communicating their ideas to others and whether a significant amount of student talk occurred between and among groups of students. The Student/Teacher Relations subscale, while not mutually exclusive from the Communicative subscale, focuses on the types of relations teachers and students exhibit in the classroom.
No statistical differences between Korean and U.S. classrooms were found for the Communicative subscale, but significant differences were discovered within this subscale on the item level for the following two items:

Item 18: There was a high proportion of student talk and a significant amount of it occurred between and among students. U.S. teachers were rated significantly higher $(t=-2.417, p=0.019)$ in comparison Korean teachers with a large effect size (Cohen's $d=1.19$ ).

Item 20: There was a climate of respect for what others had to say. U.S. teachers were rated significantly higher $(\mathrm{t}=-4.401, \mathrm{p}<.000)$ in comparison Korean teachers with a large effect size (Cohen's $d=1.90$ ).

These findings are consistent with the findings that emerged when considering the Student/Teacher Relations subscale. The Student/Teacher Relations subscale was found significantly different at the subscale level, and, on three out of the five items at the item level, the U.S. teachers were rated significantly higher than the Korean teachers. On the subscale level, the Korean teachers were rated significantly lower on this subscale. In addition, the following items within the subscale were consistently rated less descriptive of Korean classrooms (see Table 4):

Item 21: Active participation of students was encouraged and valued. U.S. teachers were rated significantly higher $(\mathrm{t}=-2.449, \mathrm{p}=0.017)$ in comparison to Korean teachers with a large effect size (Cohen's $\mathrm{d}=1.60)$.

Item 23: In general the teacher was patient with students. U.S. teachers were rated significantly higher $(\mathrm{t}$ $=-5.597, \mathrm{p}<.000)$ in comparison to Korean teachers with a large effect size (Cohen's $d=2.60)$.

Item 25: The metaphor "teacher as listener" was very characteristic of this classroom. U.S. teachers were rated significantly higher $(\mathrm{t}=-3.042, \mathrm{p}=0.006)$ in comparison to Korean teachers with a large effect size (Cohen's d = 1.13).

The Student/Teacher Relations subscale was conceptualized in the observation tool as part of the classroom culture. These findings are reflective of what others investigating Korean classrooms have found (Kim, Fisher, \& Fraser, 2000; Lee \& Fraser, 2000; Lee, Fraser, \& Fisher, 2003). This finding along with the others reference suggests that 'teacher-dominated' classrooms in Korea may inhibit teaching and learning framed by constructivism, at least more so than in their U.S. counterparts' classrooms.

\section{Summary}

This research has allowed us to better understand the similarities and differences occurring when comparing the Korean and U.S. classrooms sampled. The similarities and differences will each be summarized next and considered in the context of constructivism. 


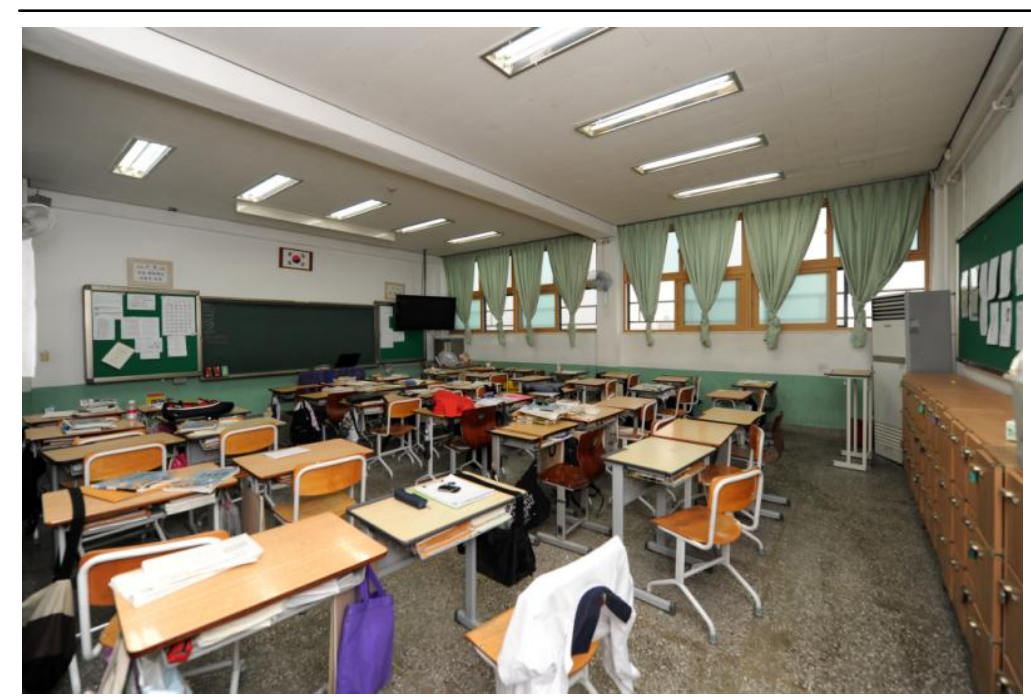

Figure 1. Sample Korean science classroom

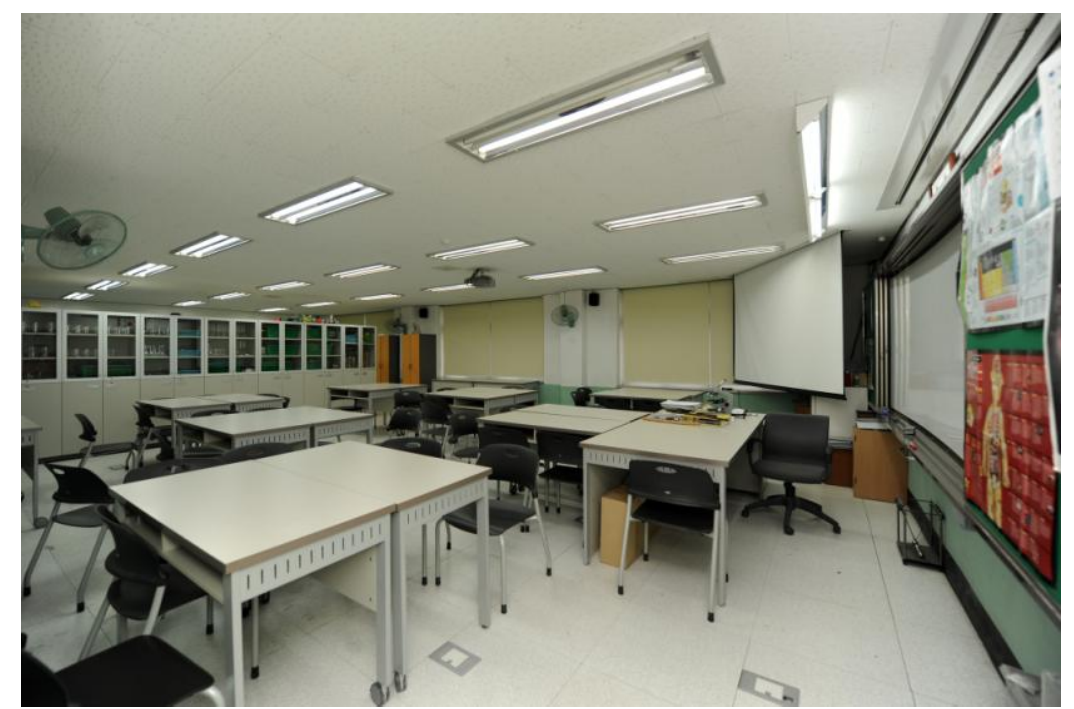

Figure 2. Sample Korean science laboratory

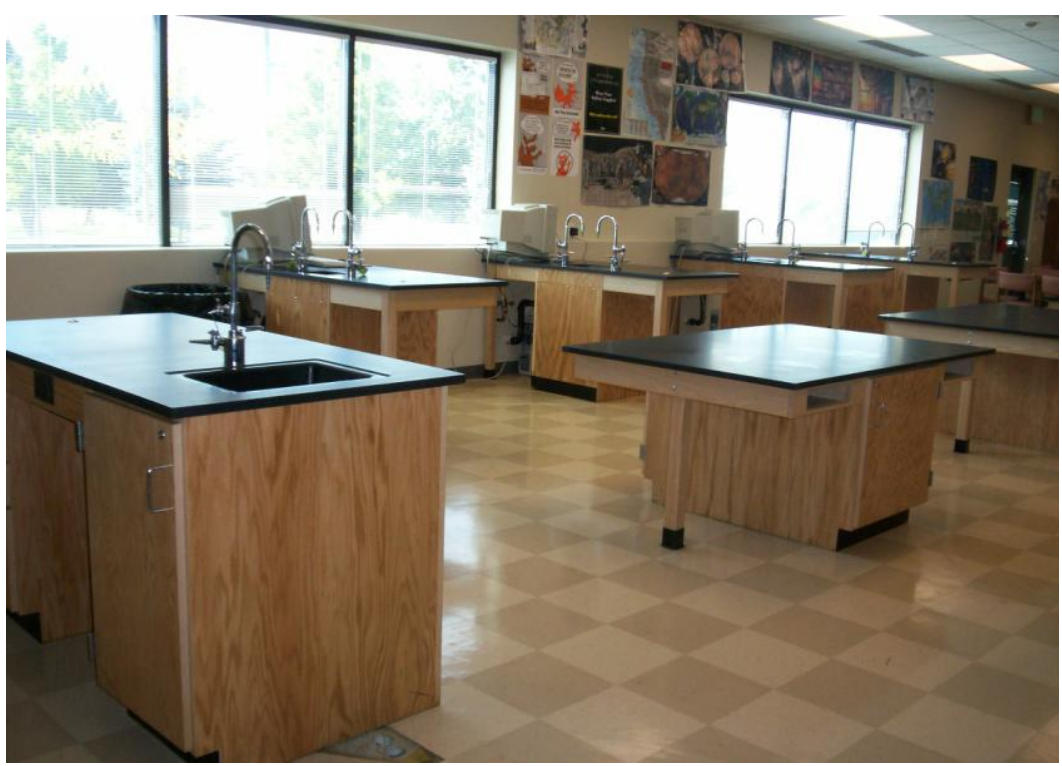

Figure 3. Sample U.S. science laboratory 


\section{Similarities}

Generally speaking, comparisons of classrooms from both countries revealed more similarities than differences. As noted earlier, while there are some signs of constructivism underpinnings in the lessons observed, for the most part, significant room still exist for improvement in both countries. This is evidenced in the lack of overall significant differences in how the classrooms were rated, as well as the lack of overall significant differences in each subscale of the RTOP, except for the manner in which teachers and students relate to one another in science classrooms. Teachers from both countries were also rated similarly low for several facets of reform teaching except when considering the content focus of the science lessons in which students engaged.

As these findings are considered in the context of constructivism underlying standards documents in both countries, concern for whether students are able to effectively construct meaningful understandings in science arises. Our research revealed little consideration for students' prior knowledge in how lessons were designed, little science process emphasized that might empower students to explore and create ideas based on concrete experiences, and little emphasis on communication occurring among students in either country. In effect, the educative approaches observed were more aligned to previous research from both countries where teacher-dominated classrooms were the norm (Lee \& Fraser, 2000; Lee, Fraser, \& Fisher, 2003; NRC, 2005; O'Sullivan \& Weiss, 1999; Windschitl, 2003) and science classrooms were less likely to engage students actively to "create, interpret, and reorganize knowledge" (Gordan, 2008, p. 324). Sample photos of the physical environment of both Korean and U.S. classrooms are provided in Figures 1-3 below. As can be seen in these photos, the physical environments in both countries does suggest that space for student engagement in reform science characterized by active scientific inquiries is available in Korea and U.S. science laboratory settings (Figure $2 \& 3$ ).

\section{Differences}

The differences between the two countries were most pronounced when considering student and teacher relations. As with previous studies investigating Korean classrooms (Kim, Fisher, \& Fraser, 2000; Lee, Fisher, \& Fraser, 2003), our findings revealed significantly less 1) value and encouragement for student active participation, 2) patience with students, and 3) listening to students on the part of the teacher in Korean science classrooms when compared to U.S. classrooms.

When considered together with other subscales of the RTOP, the differences found between Korean and
U.S. classrooms suggest that while both sets of classrooms were rated highest with respect to supporting students learning content when 'within' country subscale comparisons were made (e.g. Korean teachers Propositional subscale ratings vs. Korean teachers Procedural subscale ratings, etc.), the U.S. teachers were rated higher with respect to such reform teaching factors as Student/Teacher Relations valued in two countries' national standards documents.

\section{CONCLUSION, LIMITATIONS, AND IMPLICATIONS}

This research was completed to investigate Korean and U.S. 9-12th grade science classrooms and any similarities and differences between two countries. Our findings have led us to conclude that there is still significant room for improvement in both Korea and the U.S. in aligning student experiences in science classrooms with those visions outlined by reform efforts framed by constructivist principles.

In addition, both countries were rated highest on the Propositional subscale, which indicates the quality of content emphasized in the classrooms observed. These findings signal that, for the most part, teachers in both countries were focused on student learning content knowledge with limited regard for developing student understandings about processes of science. Most science educators agree that student learning in science is contingent upon student's understanding of both science process and content. Our findings reveal, however, that for the most part this is occurring in a limited fashion in Korean and U.S. science classrooms.

An additional concern emerges regarding reform efforts in both countries as the extent to which students are communicating in the science classroom is considered. While the U.S. classrooms were rated significantly higher than Korean classrooms in this area, the level of this occurrence in both countries was still considered low. These findings raise concern about whether or not student learning is being inhibited by the lack of opportunities for social interactions. In both countries, the lack of opportunities for students to share with peers is cause for concern in that it deprives students from negotiating and constructing knowledge with others and their community at the time they are learning science.

These findings suggest that while there are many different influences converging to shape science instruction in both countries, generally speaking, the instruction is similar. Professional developers in both countries have unique, but also somewhat similar challenges facing them as they work to align instruction with reform efforts framed by constructivism. These challenges include: 
- increasing the emphasis on process without losing focus of science content to provide students with a more holistic understanding of science and the nature of science,

- increasing the communication occurring in classrooms to afford students opportunities to participate in social construction of knowledge much like they do out of the classroom and will do into the future, and

- sharing science lessons so that they are more attuned to developing learning communities sensitive to directions forged by students.

\section{Limitations of the study}

There were several limitations to this study, some of which have already been acknowledged (i.e. 1) number of teachers sampled, 2) number of teachers observed in each discipline, as well as 3) the years teachers were observed). In addition to these, the fact that no crossover ratings were completed whereby Korean researchers rated U.S. classroom or U.S. researchers rated Korean classrooms was also seen as a possible limitation. Confidence in the ratings that did occur are strengthened by the achievement of inter-rater agreement prior to the study with agreement at or above .80 (McDavid \& Hawthorn, 2005), So, while the limitations are present, it is believed that much could be gained in comparing these convenience samples as long as the limitations were made transparent at the outset.

\section{Implications}

These two countries were initially chosen for investigation because Asian countries (including Korea) typically outperform U.S. students in science on international assessments. These countries were selected to investigate whether reform teaching could help to explain theses differences. As discussed, differences were found, but these generally did not favor Korean teachers' practice. In all cases, when significant differences were found in reformed teaching practices outlined by the nations' standards documents, the U.S. teachers were rated higher. While this seems counterintuitive given the opposite findings on international science achievement measure, it is explained if the extent to which reformed teaching was found in classrooms from both countries is considered. Both countries were rated fairly low overall in the level of reformed teaching that was observed (i.e. Korean average overall RTOP rating $46.50 / 100$ and U.S. average overall RTOP rating 53.60/100). These findings suggest that while differences were found, it is unlikely that reformed teaching practices are strong enough to be a deciding factor in explaining science achievement differences between Asian countries and the U.S.. Then, other factors may be able to explain the outperformance of Asian students in science (cf. Hwang, 2001).

It is hoped that this research can be used to shape future professional development efforts in both countries and to stimulate further studies, including qualitative ones, to compare and understand science classroom features in different cultures. It is recommended as well that factors of science learning environment such as the number of hours in science class per week, cultural contexts, and educational values should be counted in the future for better interpretation of findings emerging from different countries.

\section{REFERENCES}

Adamson, A.E., Banks, D., Burtch, M., Cox III, F., Judson, E., Turley, J.B., Benford, R., \& Lawson, A.E. (2003). Reformed undergraduate instruction and its subsequent impact on secondary school teaching practice and student achievement. Journal of Research in Science Teaching, 40(10), 939-958.

Aldridge, J., \& Fraser, B. (2000). A cross-cultural study of classroom learning environments in Australia and Taiwan. Learning Environments Research, 3, 101-134.

American Association for the Advancement of Science. (1990). Science for all Americans. New York: Oxford University Press.

American Association for the Advancement of Science. (1993) Benchmarks for science literacy. Washington, DC: Author.

Banilower, E. (2002). The status of high school physics teaching. Retrieved November 7, 2008 from http://2000survey.horizon.research.com/reports/high_ physics.php

Bhattacharya, K., \& Han, S. (2001). Piaget and cognitive development. In M. Orey (Ed.), Emerging perspectives on learning, teaching, and technology. Retrieved October 24, 2008 from http://projects.coe.uga.edu/epltt/

Fairclough, N. (1995). Critical discourse analysis: The critical study of language. Harlow, England: Longman Group.

Fraser, B. (1996). NARST's expansion, internationalization and cross-nationalization: History in the making. Presidential address presented at the annual meeting of the National Association for Research in Science Teaching, St Louis, MO.

Gordon, M. (2008). Between constructivism and connectedness. Journal of Teacher Education, 59(4), 322331.

Hruby, G. G. (2002). Social constructivism and social constructionism. In Guzzetti, B. (Ed.), Encyclopedia of Literacy Research in America. Santa Barbara, CA: ABCCLIO Press.

Hwang, Y. (2001). Why do South Korean students study hard? Reflections on Paik's study. International Journal of Educational Research, 35, 609-618.

Kim, H., Fisher, D., \& Fraser, B. (2000). Classroom environment and teacher interpersonal behavior in secondary school classes in Korea. Evaluation and Research in Education, 14, 3-22. 
Kim, M. \& Tan, A. (2010). Rethinking Difficulties of Teaching Inquiry-Based Practical Work: Stories from elementary pre-service teachers, International Journal of Science Education,First published on: 10 May 2010 (iFirst).

Lee, J. (1998). Missing Links in International Education Studies: Comparing the U.S. with East Asian Countries in TIMSS. ERIC Document Reproduction Service NO. ED422387.

Lee, S., \& Fraser, B. J. (2000). The constructivist learning environment of science classrooms in Korea. Paper presented at the 31st Annual Conference of the Australasian Science Education Research Association, Fremantle.

Lee, S., Fraser, B., \& Fisher, D. (2003). Teacher-student interactions in high school science classrooms. International Journal of Science and Mathematics Education, 1, 67-85.

Maclsaac, D., \& Falconer, K. (2002) Reforming physics instruction via RTOP. The Physics Teacher, 40(8), 479485.

McDavid, J.C. and Hawthorn, L.R.L. (2005). Program Evaluation and Performance Measurement: An Introduction to Practice. Thousand Oaks, CA: Sage.

Ministry of Education (MOE) (1997). The $7^{\text {th }}$ Curriculum: Science Curriculum. Seoul, Korea: Author. (in Korean)

Ministry of Education and Human Resources Development (MOE HRD) (2007). Science Curriculum. Seoul, Korea: Author. (in Korean)

National Council of Teachers of Mathematics (NCTM). (2000). Principles and Standards for School Mathematics. Reston, VA: Author.

National Research Council (NRC). (1996). The National Science Education Standards. Washington, DC: National Academy Press.

National Research Council (NRC). (2000). Inquiry and the National Science Education Standards. Washington, DC: National Academy Press.

National Research Council (NRC). (2005). America's Lab Report: Investigations in High School Science. Washington, DC: National Academy Press.

National Science Teachers Association (NSTA). (2007). NSTA position statement scientific inquiry. Retrieved $\begin{array}{llll}\text { November } & 7, & 2008 & \text { from }\end{array}$ http://www.nsta.org/about/positions/inquiry.aspx

O'Sullivan, C.Y., \& Weiss, A.R. (1999). Student work and teacher practices in science. U.S. Department of Education. Office of Educational Research and Improvement. National Center for Education Statistics. NCES 1999-455.

Oxford, R. (1997). Constructivism: Shape-shifting, substance, and teacher education applications. Peabody Journal of Education, 72(1), 35-66.

Palmer, D. (2005). A motivational view of constructivist informed teaching. International Journal of Science Education, 27(15), 1853-1881.

Piburn, M., Sawada, D., Falconer, K., Turley, J. Benford, R., \& Bloom, I. (2000). Reformed Teaching Observation Protocol (RTOP). ACEPT IN-003.

Sawada, D., Piburn, M., Judson, E., Turley, J., Falconer, K., Benford, R., \& Bloom, I. (2002). Measuring reform practices in science and mathematics classrooms: The Reformed Teaching Observation Protocol. School Science and Mathematics, 102(6), 245-253.
Smith, P. (2002). The status of high school chemistry teaching. Retrieved November 7, 2008 from http://2000survey.horizonresearch.com/reports/high_ chemistry.php

SPSS (Nov. 2007). Statistical Package for the Social Sciences for Windows, Rel. 16.0.1. 2007. Chicago: SPSS Inc..

Suter, L. (2000). Is student achievement immutable? Evidence from international studies on schooling and student achievement. Review of Educational Research, 70(4), 529545.

Vygotsky, L. S. (1978). Mind in society: The development of higher psychological processes. Cambridge, MA: Harvard University Press.

Weiss, I (2002). The status of secondary earth science teaching. Retrieved November 7, 2008 from http://2000survey.horizonresearch.com/reports/sec_earthscience.php

Windschitl, M. (1999). The challenges of sustaining a constructivist classroom culture. Phi Delta Kappan, 80, 751-755.

Windschitl, M. (2003) Inquiry projects in science teacher education: What can investigative experiences reveal about teacher thinking and eventual classroom practice? Science Education, 87(1), 112-143.

Wood, K. (2002). The status of high school biology teaching. Retrieved November 7, 2008 from http://2000survey.horizonresearch.com/reports/high_ biology.php

Zhou, Z., \& and Peverly, S. (2004). Cross- and within-cultural variations in children's understanding of distance, time, and speed interrelationships: a follow-up study, The Journal of Genetic Psychology, 165, 5-27.

Zhou, Z., Peverly, S., Boehm, A., \& Chongde, L. (2000). American and Chinese children's understanding of distance, time, and speed interrelations, Cognitive Development, 15, 215-240.

\section{$\diamond \diamond \diamond$}

